\title{
Neuro-Fuzzy prediction of alumina-supported cobalt vanadate catalyst behavior in the Fischer-Tropsch process
}

\author{
Mohammad Ali Takassi a,*, Abolfazl Gharibi Kharaji b, \\ Morteza Esfandyari c, and Mehdi Koolivand Salooki d \\ a Science Department, Petroleum University of Technology, Ahwaz, 6198144471, Iran \\ b Chemical Engineering Department, Petroleum University of Technology, Ahwaz, 6198144471, Iran \\ c Chemical Engineering Department, Ferdowsi University, Mashhad, 9143454532, Iran \\ d Chemical Engineering Department, Tehran University, Tehran, 1855653423, Iran \\ *Corresponding author at: Science Department, Petroleum University of Technology, Ahwaz, 6198144471, Iran. \\ Tel.: +98.912.57884301; fax: +98.611.5551223. E-mail address: takassi@put.ac.ir (M.A. Takassi).
}

\section{ARTICLE INFORMATION}

Received: 08 January 2013

Accepted: 23 January 2013

Online: 30 June 2013

\section{KEYWORDS}

\section{Catalyst}

$\mathrm{Co}-\mathrm{V} / \mathrm{Al}_{2} \mathrm{O}_{3}$

ANFIS model

Nano catalyst

Fischer-Tropsch

Neuro-Fuzzy prediction

\begin{abstract}
Alumina-supported cobalt vanadate multitransition-metal catalyst was prepared by impregnation method. The catalyst was characterized using X-ray diffraction, Fourier transform infrared spectroscopy, Brunauer-Emmett-Teller, X-ray fluorescence and Transmission electron microscopy. The cobalt/vanadium catalyst was employed for FischerTropsch process in an autoclave reactor. The evaluation of this catalyst occurred at different temperature (423-623 K), over a pressure range of 10-50 bars with the Syngas $\mathrm{H}_{2} / \mathrm{CO}$ ratio varying from 2 to 6 . The catalyst gave a high and selective conversion of syngas into methane. The degree of syngas conversion increased with increasing temperature and pressure. The adaptive Neuro-Fuzzy inference system (ANFIS) model has been applied for the training of the fuzzy system and the test set was applied to evaluate the performance of the system including moving average error (MAE), mean square error (MSE), root mean square error (RMSE) and mean absolute percentage error (MAPE). The results exposed that the predicted values from the model were in good agreement with the experimental data.
\end{abstract}

\section{Introduction}

Supported vanadium oxides have been studied extensively as they catalyse a number of industrially significant reactions [1]. These reactions include selective oxidation such as oxidative dehydrogenation of light hydrocarbons [2,3]; oxidation of o-xylene to phthalic anhydride [4]; partial oxidation of methanol to formaldehyde [5]; oxidation of sulfur dioxide to sulfur trioxide [6]; ammoxidation of aromatic hydrocarbon [7]; as well as the selective reduction of nitrogen oxides [8,9]. Vanadium oxide-promoted rhodium catalysts [10] and bimetallic nickel-vanadium catalysts [11] have been reported for hydrogenation of carbon monoxide.

The Fischer-Tropsch synthesis (FTS) is an interesting and promising pathway for the conversion of synthesis gas to transportation fuels. The FTS has been recognized as an important alternative technology to petroleum refining in the production of liquid and gaseous fuels and chemicals; syngas derived from coal, natural gas and other carbon-containing materials [12-14]. Several metals (including $\mathrm{Fe}, \mathrm{Co}, \mathrm{Ni}$ and $\mathrm{Ru}$ ) are considered as the most common active components for FTS catalysts, due to high FTS activity, low cost, flexible product distribution and favorable engineering characteristics [15].

Owing to high activity and long durability, a cobalt-based the Fischer-Tropsch (FT) catalyst is currently the catalyst of choice for the conversion of syngas to natural gas and liquid fuels. In addition, cobalt catalysts provide the best compromise between reduced costs and the high CO conversion.

They offer favorable $\mathrm{C}_{5}+$ selectivity as well as low water gas shift (WGS) activity for the synthesis of liquid fuels from natural gas. Supported cobalt catalysts with high specific rates require the synthesis of small metal crystallites at high local surface densities on support and the use of supports or alloys that enhances the rate per cobalt surface (turnover rate) [1618]. The FTS and WGS reactions are as follows:

$$
\begin{aligned}
& \mathrm{CO}+(1+\mathrm{n} / 2) \mathrm{H}_{2} \rightarrow \mathrm{CH}_{\mathrm{n}}+\mathrm{H}_{2} \mathrm{O} \\
& \mathrm{CO}+\mathrm{H}_{2} \mathrm{O} \rightarrow \mathrm{CO}_{2}+\mathrm{H}_{2}
\end{aligned}
$$

where $\mathrm{n}$ is the average $\mathrm{H} / \mathrm{C}$ ratio of the produced hydrocarbons, Anderson et al. [19] reported that the FTS activity and selectivity of cobalt based catalysts could be affected by their pore sizes. Xiong et al. [20] also indicated that the pore size of alumina support could significantly influence the $\mathrm{Co}_{3} \mathrm{O}_{4}$ crystallite diameter, catalyst reducibility and FT activity. It was also reported [21] that the support with small pores could achieve a high dispersion of supported cobalt crystallites due to their high support surface area, and those supports with large pores could diminish the diffusion resistance and provide pathways for rapid molecular transport. Moreover, it was observed [22] that larger cobalt particles located in the wider pore silica led to higher activity in FTS and lower methane selectivity than smaller cobalt particles situated in narrower pore supports.

Catalyst design could be a tedious and also a complex process involving many steps, many variables and complex interactions among these variables, making the experimental studies quite expensive and time consuming. 


\section{$\mathrm{pH}=2-3$ \\ $5\left(\mathrm{~V}_{2} \mathrm{O}_{5} .3 \mathrm{H}_{2} \mathrm{O}\right)$ \\ Brown ppt.}

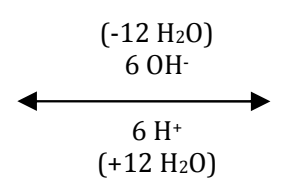

$\left(+12 \mathrm{H}_{2} \mathrm{O}\right)$

\author{
$\mathrm{pH}=6$ \\ $\left[\mathrm{V}_{10} \mathbf{O}_{28}\right]^{6-}$ \\ Orange \\ Solution
}

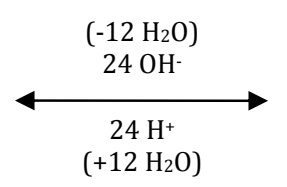

$\mathrm{pH}=12-14$
$\mathbf{1 0}^{\left.-1 \mathbf{V O}_{4}\right]^{3-}}$
Colorless $^{-}$
Solution

Scheme 1

Therefore, effective computational methods such as the adaptive Neuro-Fuzzy inference system (ANFIS) can be used to interpret the findings of experimental studies, to feed the results to the future experiments, and therefore to increase the efficiency and the effectiveness of the experimental work. ANFIS modeling has proven to be a powerful technique for complex and nonlinear problems with a strong ability to learn and predict. There is a lot of research in various fields that applied these methods for nonlinear system identification. The neural networks have been applied for modeling the greenhouse effect, simulation of $\mathrm{N}_{2} \mathrm{O}$ emissions from a temperate grassland ecosystem, and assessment of flotation experiments [23].

Takassi et al. applied experimental and fuzzy model for prediction of catalytic behavior in the process of FTS and RWGS $[24,25]$. Taskin et al. used fuzzy logic control for improving dynamic performance of fluidized catalytic cracking unit [26]. Erdem Günay and his co-worker applied ANN method to design catalyst for selective $\mathrm{CO}$ oxidation in hydrogen rich stream [27]. Sargolzaei applied neuro fuzzy model for estimation of torque in rotor wind turbine [28]. Authors in [29] applied a combination of fuzzy model and neural networks in order to identify a complex dynamic system. In addition, the flow rate of dirty amine of an adsorption column in the Khangiran gas refinery was predicted using neural network and genetic algorithm [30]. Wai and Chen also used a Neuro-Fuzzy model for the robot manipulator dynamic identification [31]. Sadrzadeh applied a Neuro-Fuzzy model coupled with a mathematical model for the prediction of zinc ions separation from wastewater using electrodialysis [32]. Erguo Li and his colleague used a Neuro-Fuzzy system in order to construct a quality predictive model for injection process [33]. Evgueniy Entchev and Libing Yang applied an adaptive Neuro-Fuzzy interface system to predict solid oxide fuel cell performance in residential micro-generation installation [34].

A comparison of artificial neural network (ANN) and Neuro-Fuzzy model has been done recently to delineate the best model for the prediction of parameters. Yasin Varol and his co-worker compared ANN and Neuro-Fuzzy models to predict the flow fields and temperature distributions due to natural convection in a triangular enclosure in [35]. Singh applied the Neuro-Fuzzy and ANN models for the prediction of cadmium removal [36]. In line with the aforementioned studies, the present study aims to develop ANFIS model in order to predict the experimental results of Fischer-Tropsch process with aluminum oxide supported cobalt-vanadium catalyst.

\section{Experimental}

\subsection{Overview}

The aim of the experiment was to investigate the activity of alumina supported $\mathrm{Co}^{3+}$ vanadium catalyst for the first time. The catalysts reported in the literature are $\mathrm{Co}^{2+}$ vanadium. The formation of pre-catalyst is explained in the text. The partial reduction of cobalt/vanadate pre-catalyst was performed in a batch reactor with hydrogen gas at a pressure of 40 bars and temperature of $873 \mathrm{~K}$ for 5 hours. The experiments were run successively. During reduction, the color of the pre-catalyst changed from pale orange to dark black. $100 \mathrm{~g}$ of catalyst was placed in a one liter volume stainless steel autoclave reactor, as described in the paper. The catalytic activity of the alumina supported $\mathrm{Co}^{3+}$ vanadium catalyst was investigated. The effect of temperature on product distribution was studied in the range of 473 to $623 \mathrm{~K}$; reaction partial pressure of $35 \mathrm{bar}$; reaction time of 1 hour and the ratio of $\mathrm{CO}: \mathrm{H}_{2}=1: 4$, the threshold temperature is $443 \mathrm{~K}$. The effect of partial pressure on product distribution was also studied in the range of 10 bars to 50 bars. The effect of syngas ratio in the product distribution was investigated with the range of $\mathrm{CO}: \mathrm{H}_{2}$ ratios of $1: 2,1: 4$ and 1:6. Our experiments demonstrated that $\mathrm{Co}^{3+} / \mathrm{V}$ catalyst is very active and selective for production of methane.

\subsection{Synthesis}

Vanadium pentoxide dissolves in aqueous sodium hydroxide to give a colorless solution. In high $\mathrm{pH}$ solution vanadium is present as $\mathrm{VO}_{4}^{3-}$ anion [37]. When the basicity is reduced a series of complicated reactions occur [38,39]. In the $\mathrm{pH}$ range of 2-6 the main species is the orange decavanadate ion [40].

One half mole of vanadium pentoxide $\left(\mathrm{V}_{2} \mathrm{O}_{5}: 3 \mathrm{H}_{2} \mathrm{O}\right)$ Baker, was dissolved in $3.1 \mathrm{M}$ sodium hydroxide in $1 \mathrm{~L}$ distilled water. One tenth mole of hydrogen peroxide was added to complete oxidation to the $\mathrm{V}^{+5}$ states. The slightly yellow solution of $\mathrm{Na}_{3} \mathrm{VO}_{4}$ was formed. The solution was filtered to remove some brown solid impurities. Then the solution was acidified slowly with $6 \mathrm{M}$ nitric acid down to $\mathrm{pH}=6.0$. This was best accomplished by adding the acid drop wise, while the solution was stirring by a magnetic stirrer. Around $\mathrm{pH}=6.5$ the color of the solution turned bright orange as decavanadate ions had formed. The decavanadate anion was deposited on the nano aluminum oxide catalyst support. For every $3 \mathrm{~g}$ of complex, $11 \mathrm{~g}$ of aluminum oxide powder was added to the solution.

The solution was heated and stirred with a high speed mechanical stirrer for 10 hours. The solution was colorless, indicating no decavanadate anion was left in the supernatant solution. 0.1 mole of the cobalt complex $\left[\mathrm{Co}\left(\mathrm{NH}_{3}\right)_{6}\right] \mathrm{Cl}_{3}$ was dissolved in sufficiently warm distilled water to obtain a dark orange to dark red solution. Then the cobalt complex was added drop-wise to the chemisorbed/alumina slurry, when stirring continued for 10 more hours. Pre-catalyst $\left[\left(\mathrm{NH}_{3}\right)_{6} \mathrm{Co}\right]_{2}\left[\mathrm{~V}_{10} \mathrm{O}_{28}: \mathrm{Al}_{2} \mathrm{O}_{3}\right]$ was filtered. The filtrate was colorless. The pre-catalyst was washed with distilled water to remove the ionic co-products, and then gently dried in an oven. The cobalt/vanadate pre-catalyst is pale orange and insoluble and unreactive in the water at 273-373 K. These equilibrium reactions are summarized in the Scheme 1 [41].

The partial reduction of cobalt/vanadate pre-catalyst was performed in a batch reactor with hydrogen gas at pressure of 40 bars and temperature of $873 \mathrm{~K}$ for 5 hours. During reduction, the color of the pre-catalyst changed from pale orange to dark black. The following procedure for syngas catalysis was followed: $100 \mathrm{~g}$ of the cobalt/vanadium catalyst was placed in a $1 \mathrm{~L}$ volume stainless steel autoclave reactor. The reactor was allowed to equilibrate at desired temperature; syngas with certain composition and pressure was injected, and then the stirring motor was turned on; after the selected time, the syngas product was passed through a condenser to condense out the steam. The condenser was cooled by a salt and ice mixture. Then the syngas was stored in the sample 
collector for gas chromatography analysis. There was no oily material observed above the water; the water was weighed. The chromatograph was used to analyse the products. A Varian Aerograph Model $90 \mathrm{P}$ with a carbosieve B 60/80 mesh column and thermal conductivity detector (TCD), with helium as carrier gas was used for $\mathrm{CO}, \mathrm{CO}_{2}$, and $\mathrm{CH}_{4}$.

\subsection{Reactor System}

The catalyst evaluation was carried out in $1 \mathrm{~L}$ volume stainless steel autoclave reactor. In gas and out gas lines were also made of stainless steel tubing. This reactor was equipped with electrical heater, magnetic stirring motor, and magnetic stirrer. The magnetic stirring motor was driven by air flow. The temperature of the reactor was controlled by a thermocouple model F2M Scientific 240 temperature programmer (Hewlett Packard). The autoclave reactor was convenient to use at medium to high pressure 150 bars and at temperature up to $1023 \mathrm{~K}$. The experimental setup is shown in Figure 1.

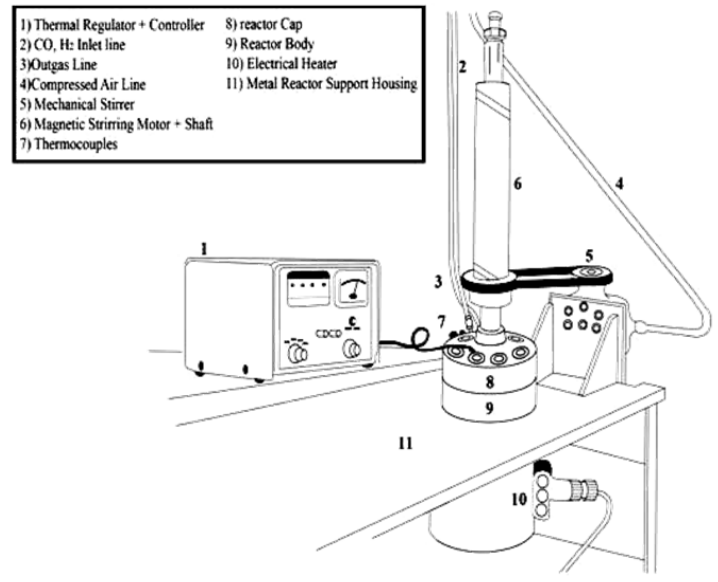

Figure 1. Stainless steel autoclave reactor used for syngas evaluation.

\section{Theory of the adaptive neural-fuzzy inference system}

Fuzzy systems and neural networks are popular techniques that have seen increasing interest in recent decades [42]. The neural networks and fuzzy systems have certain advantages over classical methods, especially when vague data is existent or the prior knowledge is required. However, the applicability of these hybrid (Neuro-Fuzzy) modeling techniques could be very limited for modeling of some engineering problems [43].

The adaptive neural-fuzzy inference system (ANFIS) is a multilayer feed forward network which uses neural network learning algorithms and fuzzy inference systems to model the input-output relationships [44]. In comparison with other learning techniques, ANFIS has a higher speed of raining, the most effective learning algorithm and simplicity of the software [45].

The basic structure of a fuzzy inference system (FIS) consists of three conceptual components: a rule base, which contains a selection of fuzzy rules; a database, which defines the membership functions (MF) used in the fuzzy rules and a reasoning mechanism, which performs the inference procedure upon the rules to derive an output. The architecture of ANFIS model is shown as Figure 2 for four inputs.

For a first-order Sugeno fuzzy model, a common rule set with two fuzzy if-then rules is the following:

Rule 1: $f_{1}=p_{1} x_{1}+q_{1} x_{2}+\ldots+k_{1} x_{6}+r_{1}$

Rule 2:

If $\mathrm{x}_{1}$ is $\mathrm{A}_{2}$ and $\mathrm{x}_{2}$ is $\mathrm{B}_{2}$ and $\ldots \mathrm{x}_{6}$ is $\mathrm{C}_{2}$; then

$\mathrm{f}_{2}=\mathrm{p}_{2} \mathrm{x}_{1}+\mathrm{q}_{2} \mathrm{X}_{2}+\ldots+\mathrm{k}_{2} \mathrm{x}_{6}+\mathrm{r}_{2}$

where $f_{i}$ is output and $p_{i}, q_{i}, \ldots k_{i}$ and $r_{i}$ are the consequent parameters of ithrule. $A_{i} B_{i}, \ldots, C_{i}$ are the linguistic labels which are represented by fuzzy sets whose membership function parameters are premise parameters [46]. The ANFIS has five layers, in which node functions of the same layer have the same function type as described follow:

The first layer, every node $\mathrm{i}$ in this layer is an adaptive node with node function:

$\mu_{\mathrm{Ai}}(x)=e^{-\left(\left(x-x^{*}\right) / \sigma^{2}\right)}$

where $\left\{\mathrm{x}^{*}, \sigma\right\}$ are premise parameters updated through hybrid learning algorithm and $x$ is input variable. At least in the basic ANFIS method these parameters are not adjustable.

The second layer calculates the firing strength for each rule quantifying the extent which any input data belongs to that rule. The output of the layer is the algebraic product of the input signals as can be given as:

$O_{2, i}=\omega_{i}=\mu_{\mathrm{Ai}}\left(x_{1}\right) \times \ldots \times \mu_{C i}\left(x_{n}\right)$

The third layer is the normalization layer. Every node in this layer calculates the ratio of the ith rule's firing strength to the sum of all rules' firing strengths.

$O_{3, i}=\bar{\omega}_{i}=\omega_{i} /\left(\omega_{i}+\ldots .+\omega_{n}\right)$

In layer four, the output of every node in fourth layer is:

$O_{4, i}=\sum \overline{\omega_{i}} f_{i}$

The fifth layer computes the overall output as the summation of all incoming signals, which represents the results of wave height or wave period as can be given as:

$O_{5, i}=\frac{\sum_{i=1}^{n} \omega_{i} f_{i}}{\sum_{i=1}^{n} \omega_{i}}$

\section{Results and discussion}

\subsection{Catalyst characterizations}

The powder X-ray diffraction (XRD) of unreduced CoV/alumina was obtained using PW1840 powder X-ray diffractometer with $\mathrm{Cu}$ tube anode operated at $40 \mathrm{kV}$ and 30 $\mathrm{mA}$ with step size 0.02 from 5 to $90^{\circ}$. XRD pattern of reduced Co-V/alumina catalyst showed some peaks of $\mathrm{V}_{2} \mathrm{O}_{5}$ at $2 \theta=26.5$, $31.8,47.1$, and $67.5^{\circ}$ and other peaks of $\mathrm{V}_{2} \mathrm{O}_{5}$ which appear in the same position as $\mathrm{Al}_{2} \mathrm{O}_{3}$ that include peaks at $2 \theta=25.6,37.8$, $52.6,61.3,66.5,68.3,76.9$, and $77.2^{\circ}$. The lines corresponding to cobalt are not observed, probably because of its amorphous form on catalyst surface.

If $x_{1}$ is $A_{1}$ and $x_{2}$ is $B_{1}$ and $\ldots x_{6}$ is $C_{1}$; then 


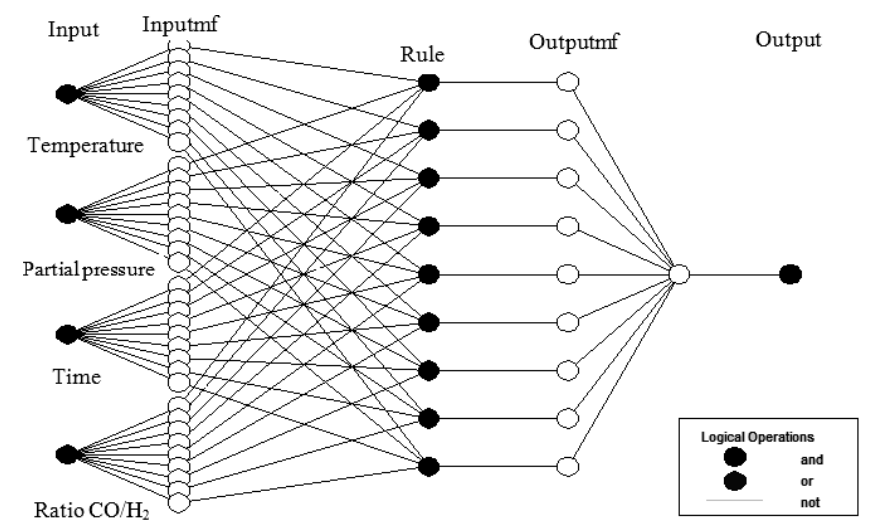

Figure 2. Architecture of an ANFIS equivalent to a first-order Sugeno fuzzy model with four inputs.

The potassium bromide disc infrared spectroscopy of unreduced Co-V/alumina was obtained using Shimadzu, FTIR4200 which indicated the presence of $\left(\mathrm{NH}_{3}\right)_{6} \mathrm{Co}^{3+}$ ion by $\mathrm{NH}_{3}$ spreading modes and the $\mathrm{V}-\mathrm{O}$ units of $\mathrm{V}_{10} \mathrm{O}_{28^{6-}}$ ion by strong $\mathrm{V}-\mathrm{O}$ stretching absorption.

The specific surface areas of the samples were determined using the Brunauer-Emmett-Teller (BET) method with adsorption of nitrogen at liquid nitrogen temperature and subsequent desorption at room temperature after initial pretreatment of the samples by degassing at $573 \mathrm{~K}$ for $1 \mathrm{~h}$. The BET surface area was obtained with a Quanta Chrome Quantasorb surface area analyzer (USA). The chemical composition of the promoted catalyst was determined by X-ray fluorescence using a XRF-1800 Shimadzu X-ray analyzer. The obtained results were shown in Table 1.

Table 1. The obtained results from BET and XRF techniques for $\mathrm{Co}-\mathrm{V} / \mathrm{Al}_{2} \mathrm{O}_{3}$ nano catalyst.

\begin{tabular}{lllll}
$\begin{array}{l}\text { Co } \\
(\mathbf{w t} \%)\end{array}$ & $\begin{array}{l}\mathbf{V} \\
(\mathbf{w t} \%)\end{array}$ & $\begin{array}{l}\text { Specific surface } \\
\text { area }\left(\mathbf{m}^{2} / \mathbf{g}\right)\end{array}$ & $\begin{array}{l}\text { Pore volume } \\
\left(\mathbf{c m}^{3} / \mathbf{g}\right)\end{array}$ & $\begin{array}{l}\text { Average pore } \\
\text { diameter }(\mathbf{n m})\end{array}$ \\
\hline 4.6 & 12.3 & 66.7 & 0.19 & 13.5 \\
\hline
\end{tabular}

Transmission electron microscopy (TEM) images were obtained by a Phillips CM-120 scanning transmission electron microscopy at $120 \mathrm{kV}$. After pre-treatment, the catalyst samples were dispersed in methanol, and the solutions were mixed ultrasonically at room temperature. Samples of this solution were dropped on the grid to obtain TEM images. Highresolution TEM image of $\mathrm{Co}-\mathrm{V} / \mathrm{Al}_{2} \mathrm{O}_{3}$ catalyst is shown in Figure 3 . The results indicated that the average particle size is $26 \mathrm{~nm}$ and the catalyst particles are in spherical form.

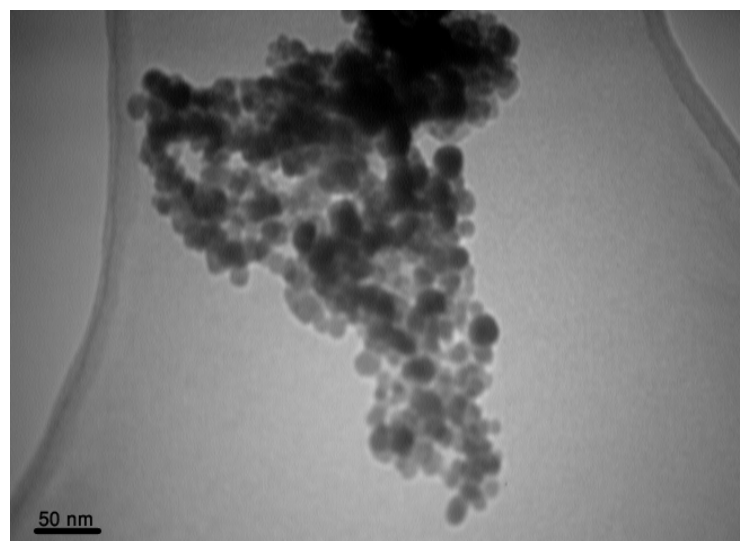

Figure 3. TEM image of $\mathrm{Co}-\mathrm{V} / \mathrm{Al}_{2} \mathrm{O}_{3}$ catalyst.

\subsection{ANFIS comparative analyses}

To achieve this objective, we used two models of Sugeno, with an automatic extraction of data from FIS [GENFIS2]. The MATLAB software was adopted for comparison purposes. Moreover, we fixed the coverage threshold to 0.01 . Table 2 shows experimental data and predicted data by ANFIS

Table 3 shows the used ANFIS information in this study with back propagation optimum method. For training the network, 41 sets of data (Table 2) were used. The training was accomplished with a 0.01 learning rate and 20,000 iterations were needed.

The fuzzy model rule surfaces showing the relationship between temperature, partial pressure, time and $\mathrm{CO} / \mathrm{H}_{2}$ ratio and $\mathrm{CH}_{4}$ are given in Figure 4. The fuzzy model rule surfaces showing the relationship between temperature, partial pressure, time, $\mathrm{CO} / \mathrm{H}_{2}$ ratio and $\mathrm{CO}_{2}$ are given in Figure 5 . The fuzzy model rule surfaces showing the relationship between temperature, partial pressure, time, $\mathrm{CO} / \mathrm{H}_{2}$ ratio and $\mathrm{CO}$ are given in Figure 6.

Figures 7 to 9 show Neuro-Fuzzy prediction of $\mathrm{CH}_{4}, \mathrm{CO}_{2}$ and CO concentration versus their experimental values in training data set. Neuro-Fuzzy model shows good $\mathrm{R}^{2}$ and also good fitness of predicted and experimental values. Figures 10 to 12 show Neuro-Fuzzy prediction of $\mathrm{CH}_{4}, \mathrm{CO}_{2}$ and $\mathrm{CO}$ concentrations versus their experimental values for the testing data set. Neuro-Fuzzy model shows good $\mathrm{R}^{2}$ and also good fitness of predicted and experimental values.

In present work, an extensive experimental data of aluminum oxide-supported di-cobalt decavanadate catalyst behavior in the Fischer-Tropsch synthesis was applied to develop a fuzzy model to predict and calculate the output variables. By comparing the obtained results using developed ANFIS model and data, it was observed that there is more qualitative and quantitative agreement between ANFIS model outputs and experimental data. Furthermore, the developed ANFIS model shows more accurate prediction over a wide range of operating conditions.

Table 4 reveals mean absolute error (MAE), mean square error (MSE), root mean square error (RMSE) and mean absolute percentage error(MAPE) for aluminum oxidesupported dicobaltdecavanadate catalyst behavior in The Fischer-Tropsch synthesis respectively. MAE, MSE, RMSE and MAPE are defined as below:

Mean absolute error (MAE) $=\frac{\sum_{i=1}^{n}\left|y_{i}^{\prime}-y_{i}\right|}{n}$ 


\begin{tabular}{|c|c|c|c|c|c|c|c|c|c|c|}
\hline \multirow{2}{*}{$\begin{array}{l}\text { Test } \\
\text { no }\end{array}$} & \multirow{2}{*}{$\begin{array}{l}\text { Temperature } \\
\left({ }^{\circ} \mathrm{C}\right)\end{array}$} & \multirow{2}{*}{$\begin{array}{l}\text { Partial Pressure } \\
\text { (bar) }\end{array}$} & \multirow{2}{*}{$\begin{array}{l}\text { Time } \\
\text { (hr) }\end{array}$} & \multirow{2}{*}{ Ratio $\mathrm{CO} / \mathrm{H}_{2}$} & \multicolumn{3}{|c|}{ Experimental values } & \multicolumn{3}{|c|}{ Predicated values } \\
\hline & & & & & $\mathrm{CH}_{4}$ & $\mathrm{CO}_{2}$ & CO & $\mathrm{CH}_{4}$ & $\mathrm{CO}_{2}$ & CO \\
\hline 1 & 200 & 35.16 & 1 & 0.25 & 0.01 & 0.03 & 0.96 & 0.02 & 0.05 & 0.95 \\
\hline 2 & 250 & 35.16 & 1 & 0.25 & 0.24 & 0.20 & 0.56 & 0.24 & 0.20 & 0.56 \\
\hline 3 & 300 & 35.16 & 1 & 0.25 & 0.67 & 0.18 & 0.15 & 0.67 & 0.18 & 0.15 \\
\hline 4 & 300 & 35.16 & 0 & 0.25 & 0.00 & 0.00 & 1.00 & 0.00 & 0.00 & 1.00 \\
\hline 5 & 300 & 35.16 & 15 & 0.25 & 0.35 & 0.14 & 0.51 & 0.35 & 0.14 & 0.51 \\
\hline 6 & 300 & 35.16 & 20 & 0.25 & 0.44 & 0.16 & 0.40 & 0.44 & 0.16 & 0.40 \\
\hline 7 & 300 & 35.16 & 25 & 0.25 & 0.52 & 0.19 & 0.29 & 0.52 & 0.19 & 0.29 \\
\hline 8 & 300 & 35.16 & 10 & 0.25 & 0.23 & 0.11 & 0.66 & 0.20 & 0.13 & 0.57 \\
\hline 9 & 300 & 35.16 & 30 & 0.25 & 0.59 & 0.20 & 0.21 & 0.52 & 0.19 & 0.29 \\
\hline 10 & 350 & 35.16 & 1 & 0.25 & 0.81 & 0.07 & 0.12 & 0.81 & 0.07 & 0.12 \\
\hline 11 & 473 & 35.16 & 1 & 0.25 & 0.05 & 0.92 & 0.03 & 0.05 & 0.92 & 0.03 \\
\hline 12 & 473 & 35.16 & 5 & 0.25 & 0.15 & 0.75 & 0.10 & 0.15 & 0.75 & 0.10 \\
\hline 13 & 473 & 35.16 & 10 & 0.25 & 0.27 & 0.56 & 0.17 & 0.27 & 0.56 & 0.17 \\
\hline 14 & 473 & 35.16 & 20 & 0.25 & 0.35 & 0.45 & 0.20 & 0.35 & 0.45 & 0.20 \\
\hline 15 & 473 & 35.16 & 0.5 & 0.25 & 0.02 & 0.97 & 0.01 & 0.05 & 0.95 & 0.03 \\
\hline 16 & 473 & 35.16 & 15 & 0.25 & 0.30 & 0.51 & 0.19 & 0.34 & 0.48 & 0.22 \\
\hline 17 & 523 & 35.16 & 0.5 & 0.25 & 0.11 & 0.80 & 0.09 & 0.11 & 0.80 & 0.09 \\
\hline 18 & 523 & 35.16 & 1 & 0.25 & 0.24 & 0.56 & 0.20 & 0.24 & 0.56 & 0.20 \\
\hline 19 & 523 & 35.16 & 10 & 0.25 & 0.49 & 0.29 & 0.22 & 0.49 & 0.29 & 0.22 \\
\hline 20 & 523 & 35.16 & 15 & 0.25 & 0.64 & 0.21 & 0.15 & 0.64 & 0.21 & 0.15 \\
\hline 21 & 523 & 35.16 & 20 & 0.25 & 0.73 & 0.17 & 0.10 & 0.73 & 0.17 & 0.10 \\
\hline 22 & 523 & 35.16 & 5 & 0.25 & 0.35 & 0.44 & 0.21 & 0.38 & 0.46 & 0.18 \\
\hline 23 & 573 & 21.38 & 10 & 0.25 & 0.70 & 0.16 & 0.14 & 0.70 & 0.16 & 0.14 \\
\hline 24 & 573 & 35.63 & 10 & 0.25 & 0.81 & 0.07 & 0.12 & 0.81 & 0.07 & 0.12 \\
\hline 25 & 573 & 49.89 & 10 & 0.25 & 0.88 & 0.05 & 0.07 & 0.88 & 0.05 & 0.07 \\
\hline 26 & 573 & 35.16 & 1 & 0.25 & 0.67 & 0.14 & 0.19 & 0.67 & 0.14 & 0.19 \\
\hline 27 & 573 & 35.16 & 5 & 0.25 & 0.71 & 0.17 & 0.12 & 0.71 & 0.17 & 0.12 \\
\hline 28 & 573 & 35.16 & 10 & 0.25 & 0.81 & 0.12 & 0.07 & 0.81 & 0.12 & 0.07 \\
\hline 29 & 573 & 35.16 & 20 & 0.25 & 0.87 & 0.07 & 0.05 & 0.87 & 0.07 & 0.05 \\
\hline 30 & 573 & 35.16 & 20 & 0.25 & 0.87 & 0.07 & 0.05 & 0.87 & 0.07 & 0.05 \\
\hline 31 & 573 & 35.16 & 20 & 0.17 & 0.92 & 0.05 & 0.03 & 0.92 & 0.05 & 0.03 \\
\hline 32 & 573 & 10.64 & 10 & 0.25 & 0.51 & 0.29 & 0.20 & 0.56 & 0.26 & 0.14 \\
\hline 33 & 573 & 35.16 & 0.5 & 0.25 & 0.59 & 0.21 & 0.20 & 0.62 & 0.19 & 0.19 \\
\hline 34 & 573 & 35.16 & 15 & 0.25 & 0.85 & 0.09 & 0.06 & 0.79 & 0.08 & 0.08 \\
\hline 35 & 573 & 35.16 & 20 & 0.50 & 0.48 & 0.20 & 0.32 & 0.46 & 0.24 & 0.37 \\
\hline 36 & 623 & 35.16 & 20 & 0.25 & 0.71 & 0.14 & 0.15 & 0.71 & 0.14 & 0.15 \\
\hline 37 & 623 & 35.16 & 0.5 & 0.25 & 0.81 & 0.07 & 0.12 & 0.81 & 0.07 & 0.12 \\
\hline 38 & 623 & 35.16 & 5 & 0.25 & 0.85 & 0.06 & 0.09 & 0.85 & 0.06 & 0.09 \\
\hline 39 & 623 & 35.16 & 10 & 0.25 & 0.87 & 0.07 & 0.06 & 0.87 & 0.07 & 0.06 \\
\hline 40 & 623 & 35.16 & 15 & 0.25 & 0.89 & 0.06 & 0.05 & 0.89 & 0.06 & 0.05 \\
\hline 41 & 623 & 35.16 & 1 & 0.25 & 0.83 & 0.06 & 0.11 & 0.81 & 0.08 & 0.12 \\
\hline
\end{tabular}

Table 3. The ANFIS information used in this study by back-propagation optimum method.

\begin{tabular}{ll}
\hline Parameters & Outputs \\
\hline Number of nodes & 287 \\
Number of linear parameters & 140 \\
Number of nonlinear parameters & 224 \\
Total number of parameters & 364 \\
Number of training data pairs & 30 \\
Number of checking data pairs & 11 \\
Number of fuzzy rules & 28 \\
Epochs optimum & 150 \\
\hline
\end{tabular}

Table 4. MAE, MSE, RMSE and MAPE for $\mathrm{CH}_{4}, \mathrm{CO}_{2}$ and $\mathrm{CO}$ which modeled by ANFIS.

\begin{tabular}{lllll}
\hline Compound & \% MAE & \% MSE & \% RMSE & \% MAPE \\
\hline $\mathrm{CH}_{4}$ & 0.95 & 0.042 & 0.204 & 7.94 \\
$\mathrm{CO}_{2}$ & 0.59 & 0.015 & 0.122 & 4.52 \\
$\mathrm{CO}$ & 1.02 & 0.058 & 0.241 & 9.22 \\
\hline
\end{tabular}

Mean square error $(\mathrm{MSE})=\frac{\sum_{i=1}^{n}\left(y_{i}^{\prime}-y_{i}\right)^{2}}{n}$

Root mean square error $(\mathrm{RMSE})=\sqrt{\frac{\sum_{i=1}^{n}\left(y_{i}^{\prime}-y_{i}\right)^{2}}{n}}$

Mean absolute percentage error (MAPE) $=\frac{1}{n} \sum_{i=1}^{n}\left|\frac{y_{i}^{\prime}-y_{i}}{y_{i}}\right|$ where $y_{i}$ is the $i$ th actual value and $y_{i}^{\prime}$ is the $i$ th predicted value for the train and test data.

\section{Conclusion}

The Neuro-Fuzzy modeling can be very helpful to improve the experimental works in catalyst design. It may be combined with the statistical experimental design techniques so that highly successful models can be established using relatively small number of data points. The model best representing the data can be used to optimize the catalyst if the data points are suitable, to study the effects of the design parameters, and to predict the possible performances of the new catalysts without doing any new experiments. 

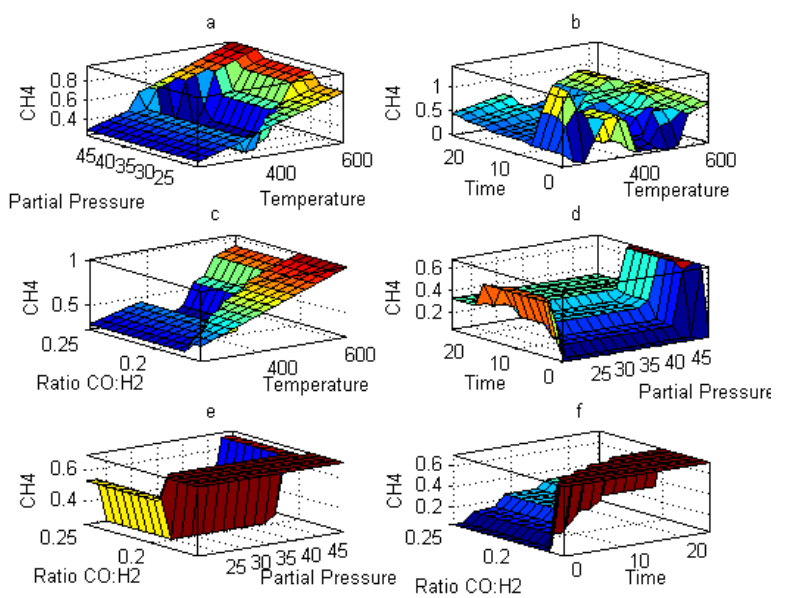

Figure 4. Fuzzy model rules surface for $\mathrm{CH}_{4}$.
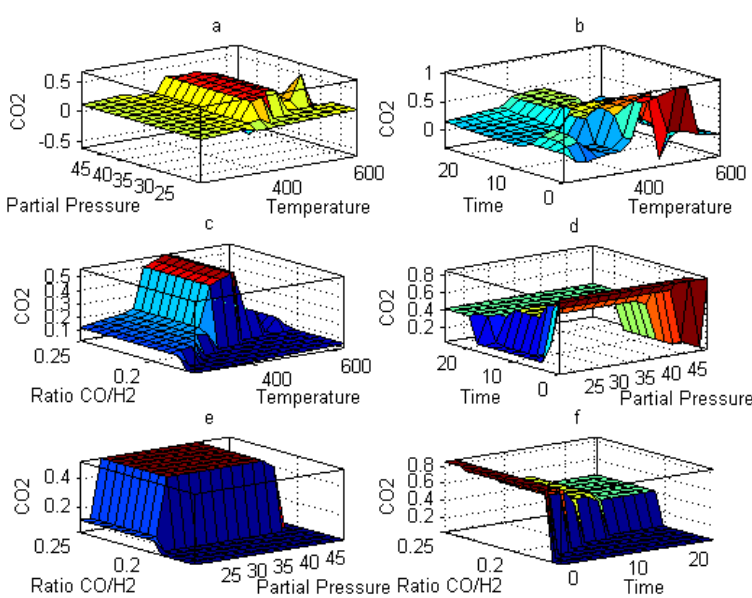

Figure 5. Fuzzy model rules surface for $\mathrm{CO}_{2}$
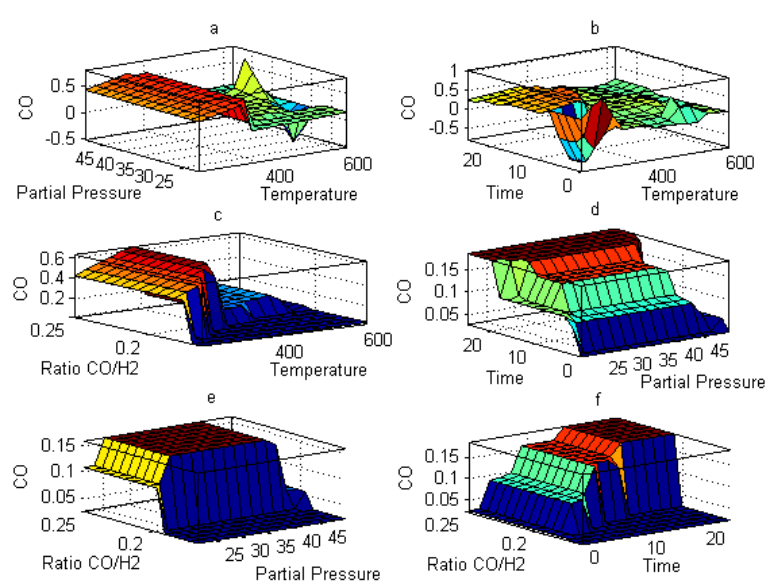

Figure 6. Fuzzy model rules surface for $\mathrm{CO}_{2}$.

The following conclusions can be drawn from the application of Neuro-Fuzzy to the prediction of the FischerTropsch synthesis as described in this paper:

- An ANFIS-based model developed to estimate the variables in a Fischer-Tropsch synthesis. Through careful selection of the input variables (here 4 variables) and designing the rules (here
58 rules) for the system and their statistical analysis, $97.53 \%$ of prediction accuracy can be obtained.

-The results were generally in compliance with experimental Fischer-Tropsch process data. However, in most cases even though limited rules and inputs were applied, the results obtained indicated a very high accuracy. This clearly shows that by increasing the number of inputs and data for each variablefor example by extending ranges of data and time of experiments, and by improving the rules used in the MATLAB package, more proper and accurate results could be expected.

- As a final remark, ANFIS is a promising predicting technique that would be effectively used for improved process control of the Fischer-Tropsch process and other units in the petroleum refinery production processes.

The study will be continued to increase the effectiveness of the proposed model by increasing and manipulating the content of the rules, data and variables (sensitivity and stability analysis) along with comparison with other classical and intelligent techniques.

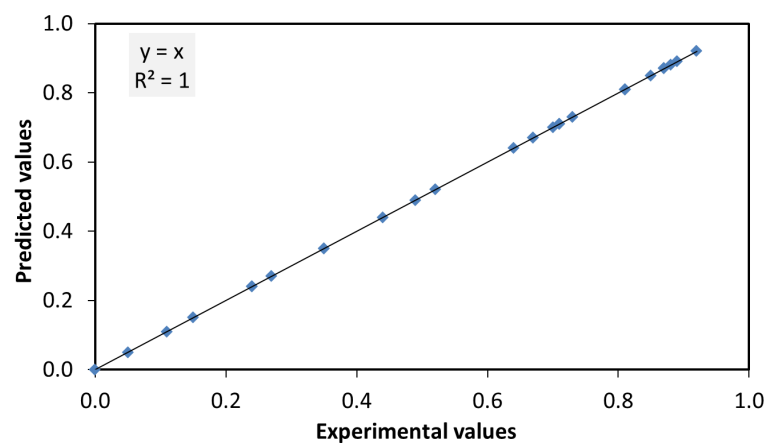

Figure 7. Predicted values of $\mathrm{CH}_{4}$ concentratinversus experimental data for training data.

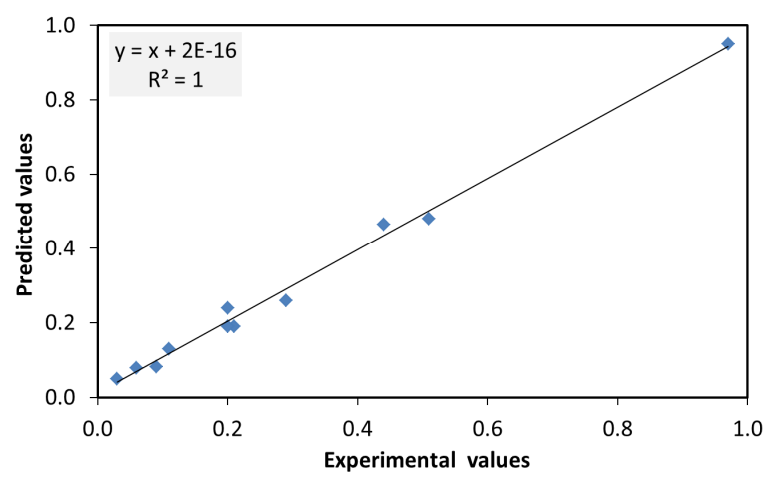

Figure 8. Predicted values of $\mathrm{CO}_{2}$ concentratin versus experimental data for training data.

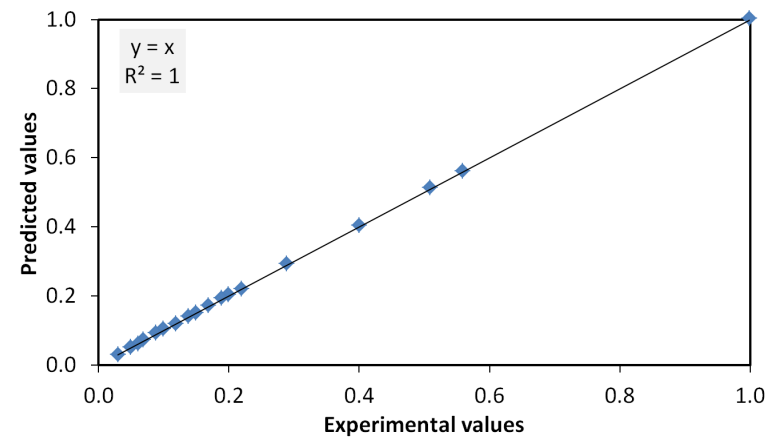

Figure 9. Predicted values of $\mathrm{CO}$ concentratin versus experimental data for training data. 


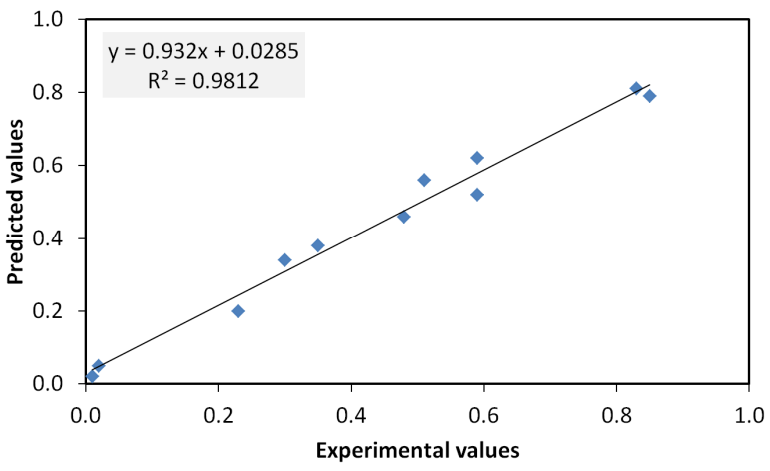

Figure 10. Predicted values of $\mathrm{CH}_{4}$ concentratin versus experimental data for testing data.

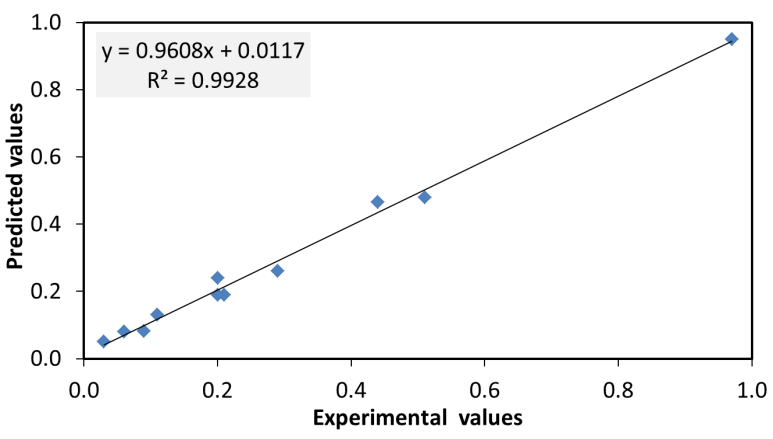

Figure 11. Predicted values of $\mathrm{CO}_{2}$ concentratin versus experimental data for testing data.

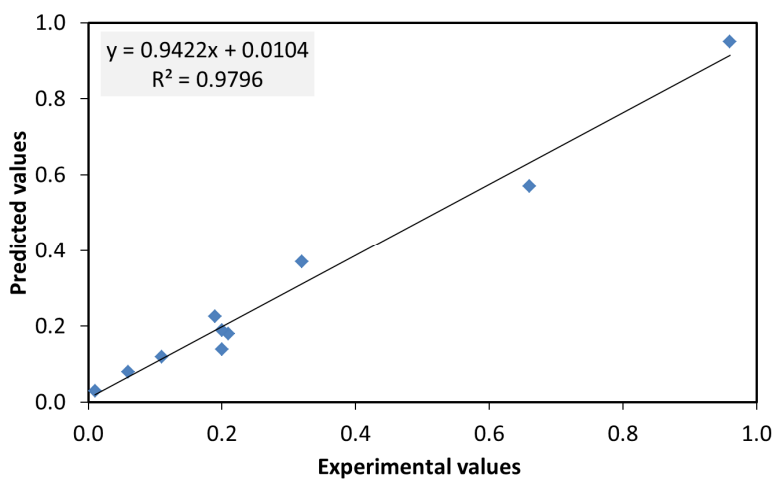

Figure 12. Predicted values of $\mathrm{CO}$ concentratin versus experimental data for testing data.

\section{Acknowledgements}

Authors gratefully acknowledge the Iranian Nano Technology Initiative Council and Petroleum University of Technology for financial support.

\section{References}

[1]. Bond, G. C.; Tahir, S. F. Appl. Catal. 1991, 71, 1-31.

[2]. Mattos, R. J. M.; Gill, S.; Rocco, A. S.; Eon, J. G. Mol. Catal. A 2002, 178, 229-237.

[3]. Solsona, B.; Dejoz, A.; Garcia, T.; Conception, P.; Lopez Nieto, J. M.; Vazquez, M. I.; Navarro, M. T. Catal. Today 2006, 117, 228-233.

[4]. Wachs, I. E.; Saleh, R. Y.; Chan, S. S.; Chersich, C. C. Appl. Catal. 1985 15, 339-352.

[5]. Feng, T.; Vohs, J. M. J. Catal. 2004, 221, 619-629.

[6]. Dunn, J. P.; Koppula, P. R.; Stenger, H. G.; Wachs, I. E. Appl. Catal. B 1998, 19, 103-117.

[7]. Martin, A.; Lucke, B. Catal. Today 2000, 57, 61-70.

[8]. Amiridis, M. D.; Duevel, R. V.; Wachs, I. E. Appl. Catal. B 1999, 20, 111122 .
[9]. Due-Hansen, J.; Boghosian, S.; Kustov, A.; Fristrup, P.; Tsilomelekis, G.; Stahl, K.; Christensen, H.; Fehrmann, R. J. Catal. 2007, 251, 459-473.

[10]. Kip, B. J.; Smeets, P. A. T.; Van Wolput, J. H. M.; Zandbergen, H. W.; Van Grondelle, J. H.; Prins, R. Appl. Catal. 1987, 33, 157-180.

[11]. Karaselcuk, R.; Inci, I.; Aksoylu, A.; Ilsen, O. Z. Appl. Catal. A 2000, 192, 263-271.

[12]. Nakhaei, P. A.; Housaindokht, M. R.; Tayyari, S. F.; Zarkesh, J. J. Nat Gas. Chem. 2010, 19, 441-445.

[13]. Anderson, R. B. The Fischer-Tropsch Synthesis, Orlando, FL; Academic Press, 1984.

[14]. Bartholomew, C. H. Surf. Sci. 1991, 64, 158-224.

[15]. Dry, M. E. J. Chem. Technol. Biot. 2002, 77, 43-50.

[16]. Iglesia, E. Appl. Catal. A 1997, 161, 59-78.

[17]. Dalai, A. K.; Davis, B. H. Appl. Catal. A 2008, 348, 1-15.

[18]. Karimi, A.; Nakhaei Pour, A.; Torabi, F.; Hatami, B.; Tavasoli, A.; Alaei, M. R.; Irani, M. J. Nat. Gas. Chem. 2010, 19, 503-508.

[19]. Xiong, H. F.; Zhang, Y. H.; Liew, K. Y.; Li, J. L. J. Mol. Catal. A 2008, 295, 68-70.

[20]. Song, D. C.; Li, J. L.; J. Mol. Catal. A 2006, 247, 206-212.

[21]. Li, H. L.; Li, J. L.; Ni, H. K.; Song, D. C. Catal. Lett. 2006, 110, 71-76.

[22]. Khodakov, A. Y.; Bechara, R.; Griboval-Constant, A. Appl. Catal. A 2003 254, 273-278.

[23]. Satish, S.; Setty, Y. P. Int. Commun. Heat Mass 2005, 32, 539-547.

[24]. Takassi. M. A. ; Koolivand, S. M. ; Esfandyari, M. Nat. Gas Chem. 2011, 20, 603-610.

[25]. Gharibi Kharaji, A.; Shariati, A.; Takassi, M. A. J. Am. Sci. 2011, 7, 1064 1068.

[26]. Taskin, H.; Kubat, C.; Uygun, O.; Arslankaya, S. Comput. Chem. Eng. 2006, 30, 850-863.

[27]. Erdem, G. M.; Yıldırım, R. Chem. Eng. J. 2008, 140, 324-331.

[28]. Sargolzaei, J.; Kianifar, A. J. Adv. Eng. Soft. 2010, 41, 619-626.

[29]. Mastorocostas, P. A.; Theochairs, J. IEEE SMC. 2002, 32, 176-190.

[30]. Seghatoleslami, N.; Koolivand, S. M.; Mohamadi, N. J. Petrol. Sci. Technol. 2011, 29, 1437-1448.

[31]. Yao, H. M.; Vuthaluru, H. B.; Tade, M. O.; Djukanovic, D. Fuel 2005, 84, 1535-1542.

[32]. Sadrzadeh, M.; Ghadimi, A.; Mohammadi, T. J. Chem. Eng. 2009, 151, 262-274.

[33]. Li, E.; Jinshou, L. J. Comp. Chem. Eng. 2002, 26, 1253-1263.

[34]. Evgueniy, E.; Libing, Y. J. Power. Sources 2007, 170, 122-129.

[35]. Huang, X.; Qi, H. Chinese Control and Decision Conference (CCDC) 2008 , 4738-4741.

[36]. Singh, T. N.; Singh, V. K.; Sinha, S. Mine. Water Environ. 2006, 25, 214219.

[37]. Cotton, F. A.; Wilkinson, G.; Murillo, C. A.; Bochmann, M. Advanced Inorganic Chemistry, 6th edition, John Wiley \& Sons, 1999.

[38]. Griffith, W. P.; Wickins, T. D. J. Chem. Soc. A 1966, 1087-1090.

[39]. Griffith, W. P. J. Chem. Soc. A 1967, 905-912.

[40]. Rossotti, F. J. C.; Rossoti, H. Acta Chem. Scand. 1956, 10, 957-984.

[41]. Cotton, F. A.; Wilkinson, C. Advanced Inorganic Chemistry, 3rd edition, Interscience Publishers, 1972.

[42]. AliyariShoorehdeli, M.; Teshnehlab, M.; KhakiSedigh, A. Fuzzy Sets Syst. 2009, 160, 922-948.

[43]. Ozger, M.; Yildirim, G. J. Adv. Eng. Soft. 2009, 40, 281-287.

[44]. Zhenga, H.; Jiangb, B.; Lu, H. J. Food Eng. 2011, 1, 10-16.

[45]. Rahmaniana, B.; Pakizeh, M.; Esfandyaria, M.; Heshmatnezhad, F.; Maskooki, A. J. Hazard. Mat. 2011, 192, 585-592.

[46]. Meharrar, A.; Tioursi, M.; Hatti, A.; Stambouli, B. Expert Syst. Appl. 2011, 38, 7659-7664. 